\title{
Digital Backpacking in the Museum with a SmartCard
}

\author{
Eva Hornecker \\ HIT Lab NZ \\ University of Canterbury \\ Private Bag 4800, Christchurch 8004, NZ \\ eva.hornecker@hitlabnz.org
}

\begin{abstract}
This paper reports on the evaluation of a digitallyaugmented exhibition on the history of modern media and our experiences with the methodic approach employed. As a central element of this exhibition visitors can buy a smartcard that enables them to store collected or selfcreated data in a 'digital backpack', which can be accessed via internet as a personalized souvenir. We have evaluated the exhibition, visitors' perceptions and usage of the card using a multi-method strategy complementing quantitative data-analysis with qualitative, ethnographic methods. This paper focuses on visitors' use and the perceived utility of the smartcard, and our experiences with using automatically generated data from interaction logfiles for analyzing visitor behavior, and with the multi-method strategy.
\end{abstract}

\section{Author Keywords}

Museums, guide systems, evaluation, smartcard, visitors.

\section{ACM Classification Keywords}

H5.m. Information interfaces and presentation (e.g., HCI): Miscellaneous.

\section{INTRODUCTION}

Museums are increasingly augmenting the museum space with digital installations and digital guide systems that deliver context-based information and recommendations. Some of these systems replace the previous technology of static audio tapes with more sophisticated, dynamic, and multimodal information [2, 19], others provide novel services or new kinds of activities, such as treasure hunts, discussions between online and local visitors $[6,10]$, or collecting souvenirs and photos [8]. How to design such systems, integrate them into the use context, and evaluate their use has become a relevant field of research for HCI, public spaces and museums being among the novel avenues that extend HCI's scope beyond the workplace.

\author{
Matthias Stifter \\ Institute of Computer Graphics and Algorithms \\ Vienna University of Technology \\ Favoritenstr. 9-11, A-1040 Vienna, Austria \\ stifter@cg.tuwien.ac.at
}

In summer 2003 the Austrian Technical Museum Vienna (TMW) opened a long-term exhibition on media history. The medien.welten exhibition combines traditional object exhibits, computer-enhanced hands-on exhibits, and a large space dedicated to modern media. As part of the exhibition visitors can buy a SmartCard. Using the card, visitors can store collected or self-created data in a 'digital backpack'. Via the museum homepage they can later-on access their digital backpack, and send e-mails to other visitors. In mid 2003 the igw institute of TU Vienna was contracted for an evaluation $[12,13]$ as an independent partner. The museum was both interested in evaluating the overall exhibition and in testing whether the automatically generated data allows tracking visitors' movement and interaction patterns. Furthermore we were to assess visitors' attitudes towards the smard.card and its actual usage. The evaluators chose a multi-method strategy, complementing quantitative dataanalysis with qualitative, ethnographically oriented methods $[5,9,16]$. Smart.card tracking data, digital backpack content and logfiles of computer-enhanced exhibits were statistically analyzed by the second author. The first author supervised and conducted the qualitative study involving $\sim 16$ hours of observation in the exhibition and an analysis of 30 semi-structured interviews with visitors. The project resulted in a 118-page project report completed in March 2004 [12] and the second author's diploma thesis [20].

We here focus on results concerning the smart.card and on its utility for visitor tracking. We first give an overview of the exhibition and our assessment approach. Then we present results on smart.card usage and visitor perceptions. At last, we discuss our experience with utilizing automatically generated data for tracking visitor behavior.

\section{THE EXHIBITION}

The central goal of the medien.welten exhibition is to arouse interest and understanding for modern media in visitors of all age groups and to increase awareness of possibilities and risks of the media society $[17,18]$. The exhibition is structured in three parts, reflected in its layout (see figure 1). The history of transmission media is shown in the right wing while the left wing presents storage and calculation media. Thematic islands start chronologically at the entrances (bottom). The convergence into today's digital media is presented in the large 'digital room' that connects the top far ends of both wings. Traditional object exhibits are placed next to interactive exhibits for hands-on 


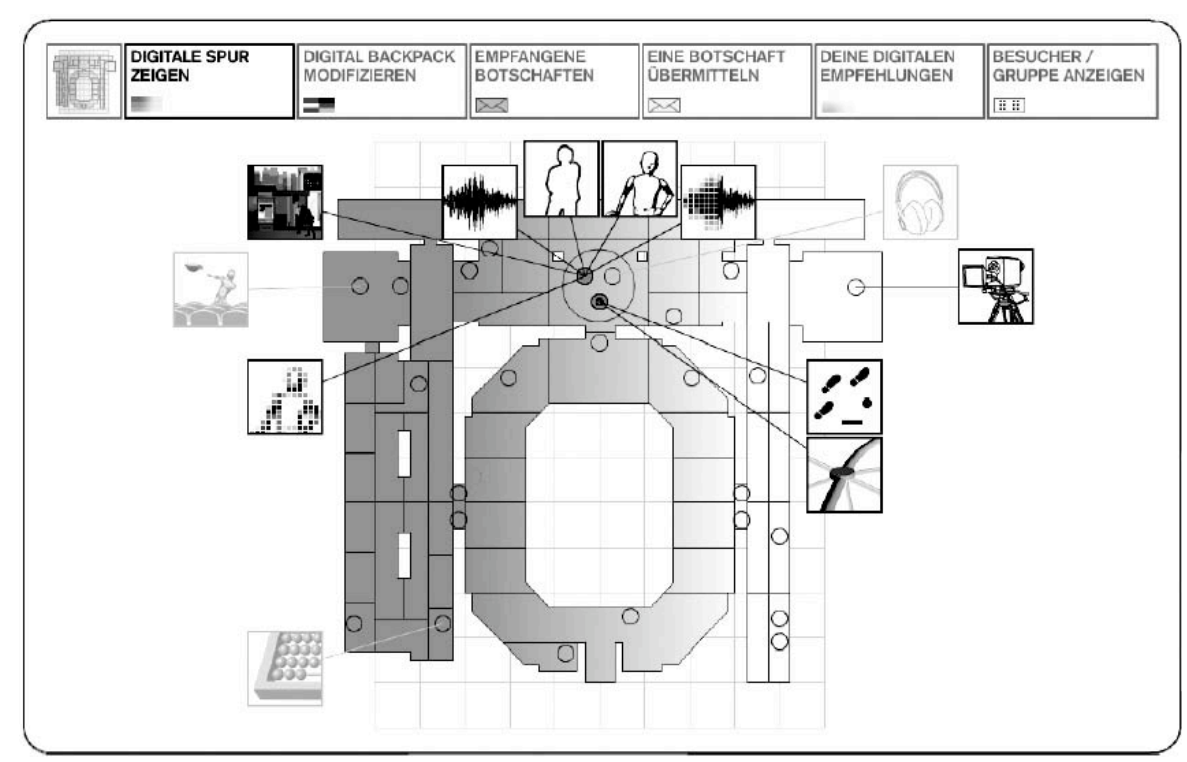

Figure 1. The digital backpack shows a map of the exhibition. Circles designate installations or terminals. Dark icons indicate stored data, grey icons unused exhibits. Bookmarks from the medien.matrix are provided with the left icon in the top row. processing and edutainment programs. Here one can go on processing ones' photo and sound samples. Digital media produced by visitors are fed into these applications, visible and accessible to others, producing traces that whither away, replaced by newer items. The inner space of the exhibition, surrounding a glass-roofed court, contains three further installations. The 'transparent human' shows fragmented parts of backpack content from detected smartcards on a glass curtain. 'Global Storage' and 'Global Net' consist of two large projections each. One shows a globe and allows selecting cities with laser pointers. Material from digital archives in these cities is downloaded and 'floats' onto the second screen where it can be selected and opened.

\section{SmartCard Concept}

experience. An example for a digitally-augmented hands-on exhibit is the abacus (figure 4) which guides visitors through calculation examples by providing feedback and instructions on the monitor sitting behind the tangible input space. Two other augmented hands-on exhibits deal with telegraphy and allow Morse coding, either with an alphabet wheel and a Morse ticker (figure 3), and simulate optical telegraphy. Other installations are purely screen-based, such as five touch screens with a guide system, and six information terminals (the 'media.matrix'). These are installed throughout the exhibition. The latter allow exploring the history of media evolution, organized in a matrix across themes and eras. Many interactive installations are placed in the 'digital room'. Most popular is the blue screen TV Newsroom (figure 2). Here visitors are led through reading the news (by instructions given on the podium). After a test run they can videotape themselves. The video is overlaid with the Austrian TV news intro and logo and then shown in public on a big screen. Well-liked by children and families are the digitization booths that allow saving photos and sound samples (figure 4). The ORF archive (a touch screen terminal) offers a selection of Austrian TV and radio samples of the last 50 years. Furthermore ten computer terminals offer a range of applications, e.g. networked games, simulations, image integral part [18]. Visitors can buy it at production cost when entering the museum. Card owners interact with the information system of the exhibition that is accessible at diverse installations and terminals. Comparing the visitor path with previous visitors allows giving recommendations of what to visit next. Digital objects created by the visitor (news video, images, sound samples, game results) and selected information (e.g. media.matrix pages, ORF archive snippets) are saved in his/her digital backpack along with objects from other exhibits the visitor interacted with.

When a card is laid onto the reader area of guide systems, one can explore ones own profile and stored content, read recommendations, and communicate with other visitors. One can configure the profile (user name, language, icon) and see where one has been. Active cards are shown (online visitors that have logged on and museum visitors) and can be sent messages. Following our early recommendations, a demo profile was developed. It enables anyone to explore the basic principle of the card. This public backpack contains the last ten videos, images and sound samples produced in the exhibition, thus strengthening the 'connect' theme of the exhibition. Using the number printed onto their smartcard as login, visitors can access their own
The exhibition concept features the smart.card as an
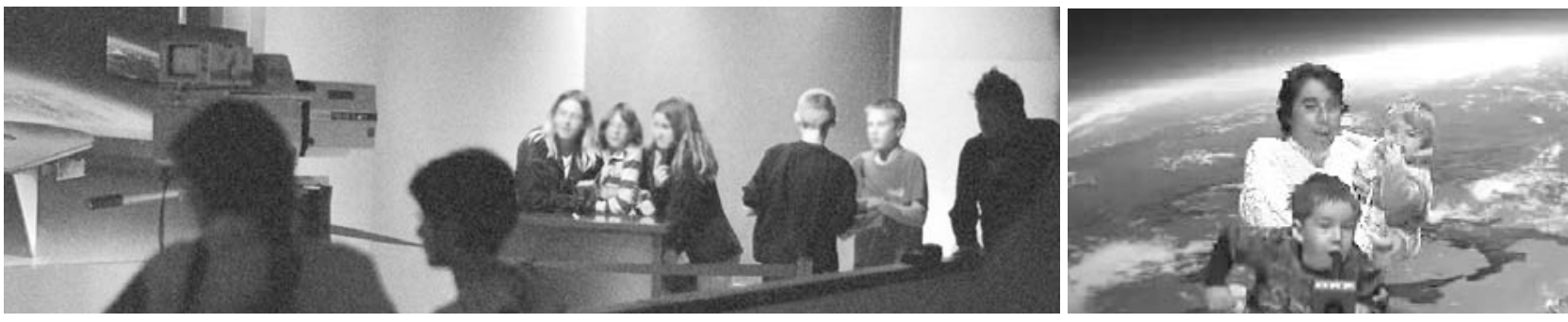

Figure 2. The 'TV Newsroom' with blue screen TV studio. Still of one video 


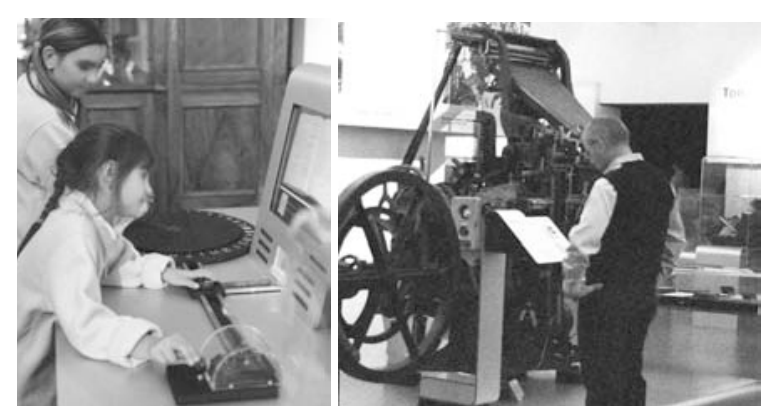

Figure 3. The telegraphy hands-on exhibit and printing press.

digital backpack via the museum homepage (www.tmw.at) and download the content. This way they can take a personal souvenir home and share it with friends and family (c.f. [8]). While they are logged in, they can use the messaging service to communicate with other visitors.

Whenever a card is registered, this is logged as starting a use 'session' of the exhibit where this happens. A session ends when the card is removed. Card tracking is based on RFID recognition. In use are card readers with short $(7 \mathrm{~cm})$ and long range $(\mathrm{ca} .70 \mathrm{~cm})$. Most interactive stations are equipped with short-range readers, requiring to put the card on a reader area or tray embedded in the station's casing. Since touch screen electronics and metal casings interfere with the electromagnetic antenna fields of long-range readers, only a few thematic islands are equipped with portals (pathway with tracking) and some installations have long-range readers, registering visitors in their vicinity.

Different from mobile guide approaches $[1,2]$ personalized information is thus presented within the exhibition on dedicated screens while the visitor carries only the card. This decreases the danger of theft for the museum. As advantage for visitors it increases screen estate and allows access of relevant information (albeit non-personalized) without a card or mobile device, offering a choice.

\section{Evaluation Approach}

Goals for assessment were to deliver recommendations for improving the exhibition, for enhancing smart.card features, and to improve knowledge on visitor tracking. We thus did not focus on individual exhibits or features.

The data collected by the system for used cards (collected content, time-stamped interactions with installations) allows tracking visitor movement and behavior. Additionally we utilized automatically generated data from computeraugmented exhibits (event logfiles) to assess 'anonymous' visitor behavior (cf. [11]). To acquire more information, the card profile was extended with a demographic questionnaire including a field for comments. In addition, visitors could fill out a questionnaire via the demo card profile. We furthermore wanted to assess visitors' attitudes towards the card and the actual card usage. Data analysis was thus supplemented with qualitative, open observation in the exhibition ( 16 hours) and 30 semi-structured interviews of 5-10 minute length with a representative sample of visitors (children, couples, pupils, senior citizens, teachers, families...) $[5,9,16]$.

Most interviews took place when visitors left the exhibition. Eight persons were given a smart.card for free, so as to interview a larger number of people with experience of the card. Interviews were taped, transcribed, and analyzed according to interview questions and emerging recurrent themes. Questions focused on the motivation to buy or not buy a card, the experience of the exhibition and the card, and suggestions for improvement. Participant observation (usually 2-3 hours per visit, extended over several months) was oriented by ethnographic approaches [5], taking field notes, subsequently extracting further research questions and observational categories. It was scheduled so as to cover high- and low-frequented times and diverse visitor types (typical days for families or school classes on day trips). At these times notices were placed at all entrances. Observations and atmospheric impressions were documented with a series of photos. Observation took place at a distance so as not to intrude on visitors. If informal conversations evolved, it became possible to walk along with visitors and to observe them more closely.

Data sources for analysis were the smart.card profiles, server logfiles, and event logfiles of installations. When designing the evaluation concept, it turned out that several software modules had to be adapted to enlarge and standardize the data set. Subsequent software enhancements caused different durations of data collection. Card profiles created between July 2003 and February 2004 were available for analysis (978 in total) while data on smart.card activity starts only in August 2003. Logging of interaction with interactive exhibits was activated in October 2003 (yielding 35120 anonymous and 2253 card sessions by
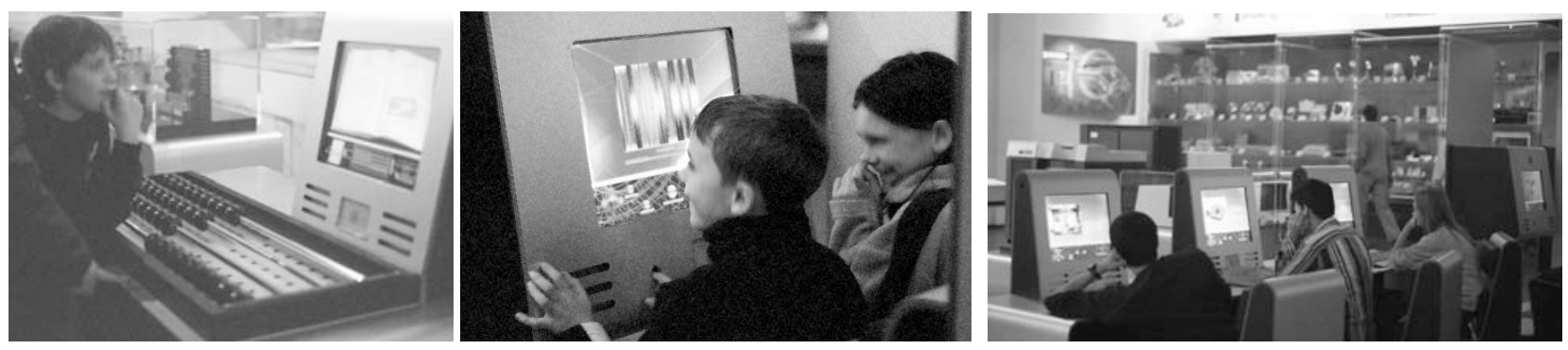

Fig. 4. Left: A family doing calculations with the Abacus. Middle: Children having fun in the digitization booth. Right: Digital room with computer terminals (background: 'shopping window' with electronic appliances from 30's to nowadays) 


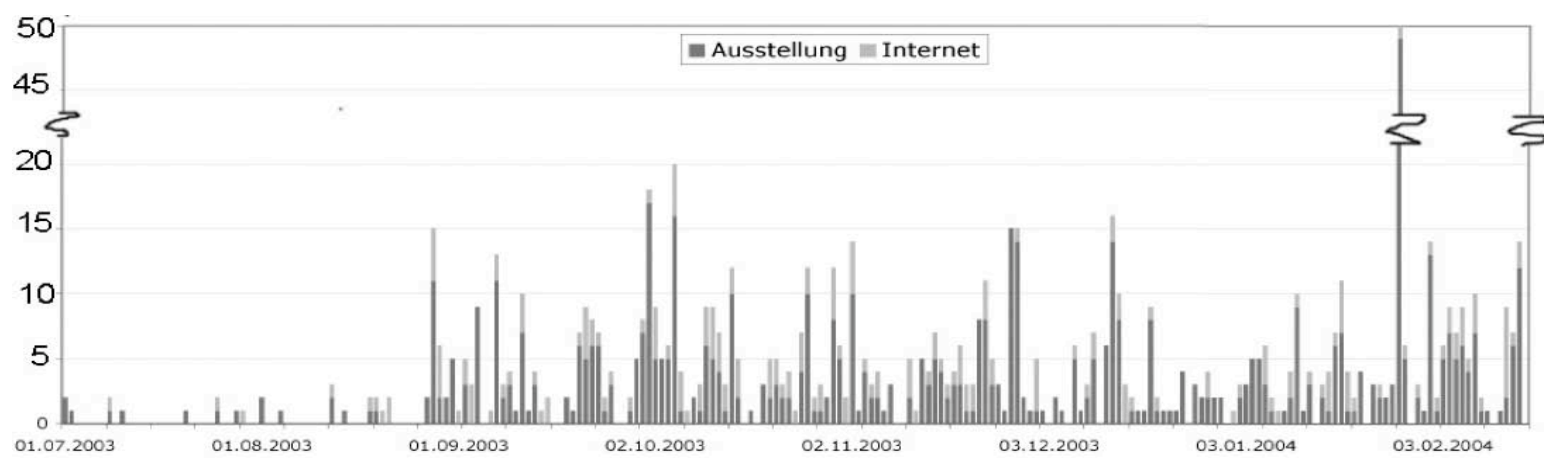

Fig. 5. Number of Smartcards in the museum (dark) and internet access (light grey) of digital backpacks 1.7.2003 to 28.2.2004

February 2004). The questionnaire was first put online in September 2003. Data for analysis stems from a second version running January to June 2004 (305). Preceding statistics (SPSS and Excel), data had to be filtered. Cards from museum personnel or given out at special events (e.g. a company dinner) were handled separately. Due to breakdowns of computers or card readers it can happen that card removal is not registered and the 'use session' of an exhibit is ended only at the end of the day. Such sessions as well as unrealistic sessions ( $>1$ hour), and the time-out ending a session were eliminated from the data set.

Different research methods suit different questions. Interviews give insight into visitors' motivation and experience. Open observation provides us with detailed accounts of the behavior of a limited number of visitors while data analysis yields statistical summaries from hundreds of visitors over long periods of time, verifying or falsifying impressions from observation. Observation and interviews generate new questions for data analysis, contextualize results, and explain data phenomena. Qualitative and quantitative analysis thus can work effectively hand in hand (method triangulation $[9,16])$.

Nevertheless data analysis is hampered by systematic blind spots. Different from approaches of continuous visitor tracking [4] we could only register visitors at specific locations [2]. Moreover, tracking requirements had not been considered when deciding upon reader placement. For example we do not know when visitors enter or leave, and only detect first and last card usage. To require visitors to explicitly lay cards onto a reader does not ensure accurate
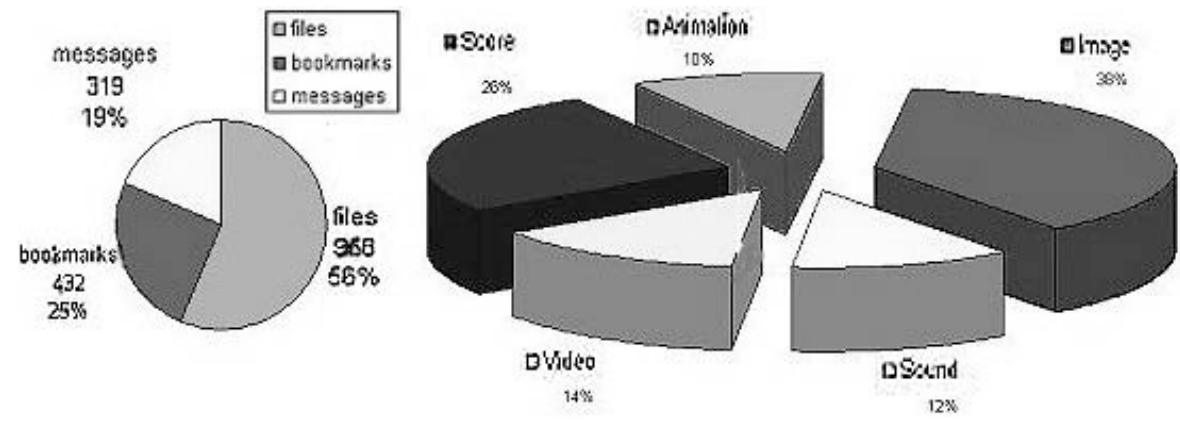

Fig. 6. Content of digital backpacks by files, messages and bookmarks (finer splitting of file types: game scores, animation, image, sound, videos) tracking. Some may explore an exhibit and only at some point remember to use the card, not use it at all, or remove it, but continue to interact. Some of the observed or interviewed visitors initially assumed it to be sufficient to swipe cards over a reader. This may result in tracked sessions shorter than the 'real' use period or in subsequent sessions representing continuous use. After two minutes of non-activity we assume an 'anonymous' visitor to have left. Two people quickly changing places thus show up in our data as a single session. In particular we do not capture noninteraction - we can't tell how many visitors ignore an exhibit (see [15]: visitors only stop at $1 / 2$ to $1 / 3$ of objects). We also can't tell how many people share a smartcard, even though interviews and observations indicate that families, couples and friends often do share cards, and frequently interact with exhibits as a group (c.f. [1, 7, 15, 19]).

\section{RESULTS OF THE EVALUATION}

\section{SmartCard Use and Differences Between Card Owners and Non-Owners}

By February 2004 a total of 1179 cards had been sold or given to visitors at special events. Profiles younger than early October were available for analysis. Visitors bought 511 cards. $14 \%$ were used in multiple museum visits (usually two or three times). All interviewed visitors with card said that they want to access their digital backpack via internet to print out, show, or send data to friends, colleagues or classmates. Yet most sounded quite skeptical about being able to access it via internet: "If it works - then I will" "I hope that it will be possible to watch it via internet" (all quotes translated). 41\% of visitors buying a card actually did access their digital backpack online. Two thirds open it more than once. While one online visit lasts on average $4 \frac{1}{2}$ minutes, overall access time sums up to 12 minutes. Visitors given the card at special events seem to differ from normal visitors as they only rarely make use of internet access and seldom change their card profile.

The smart.card proves difficult to sell as many visitors visit the exhibit as part of the museum and only stroll 
through. Interviews and observation revealed that many people stay less than 15 minutes (visitor studies, e.g. [15], give an average visit length of exhibitions within large museums of below 20 minutes). Those visitors that agreed to be given a card as gift usually were interested in the exhibition anyway. Others turned our offer down, telling us they would only stroll through. Buying the card does not seem worthwhile to them. From 30 interviewees nine had not taken notice of its existence. Only four had bought a card, of which three had needed to go downstairs again to the ticket office from the $3 \mathrm{~d}$ floor after noticing about it in the exhibition. Most buyers had specific interest in the exhibition and hoped for additional information, to save their TV news video or were curious for the new technology. The majority wanted to access their backpack to print, show, or send it to friends and family. Some used the TV studio for a birthday greeting, others wanted to take a group photo. Most card-owners interviewed and observed were keen to test card features and fill their backpack. Observations and conversation with foreign-language visitors revealed that this might be a potential user group to be specifically addressed, as the option to switch languages in the card profile enhances access to exhibition contents.

After seeing the exhibition and having the card concept explained, the majority of interviewed visitors stated interest ("For the next visit, I will buy it!"). A threshold was money, not being "a technology freak" and intended visit duration. The basic idea was rated well. Visitors liked the interactivity and the option of taking something home (c.p. [15]) and accessing data from home. Interviews revealed that the card currently mostly serves people interested in new media and offers less value to historically interested visitors (which make up a considerable portion of museum visitors according to interviews and observation). In fact most content of the digital backpack stems from the digital room. In addition content from other areas involves little actual information. On solving a lengthy calculation task on the abacus, an animation of the chicken bought in the example is saved, but no background information about the abacus. The telegraphy exhibits allow sending telegraphed messages to other visitors, but do not save information about the exhibit. Visitors furthermore suggested providing access to more content (time in the exhibition being limited) and complete contents of archives.

Buyers and interviewed test users (given the card as a gift) spend more time in the exhibition (high ratio of 45 minutes to 2 hours visits) and give better ratings (good to excellent) than non-owners (15 minutes, OK to good). This is confirmed by the questionnaire (card owners rated the exhibition with 1,79 , non-owners with 2,18 on a 1-5 scale) and data analysis showing card owners to stay on average 56 minutes. Nevertheless $25 \%$ used the smart.card less than 10 minutes. This confirms observations of some visitors, who only rarely used their card and spent most time at traditional exhibits. The following vignettes give examples for different types of visitors with cards:
- A preschool boy and his father sit in the digitization booth taking photos. The mother at the adjacent terminal is handed the card and opens the backpack. Then she joins them again and they take several group photos. Then they distribute at two terminal and open the new photos for digital image procession.

- A family with two teenage daughters walks into the blue screen TV studio. The girls take turns in reading the news lines. Their talk indicates they save these ("give me the card, then I can" - "Saving?"). The parents remind the younger one to look into the camera. At last they make a joint recording with the mother. All in all they spend 20 minutes in the studio. They seem not to be aware of only the last video being saved. Identifying their profile through the time-stamp, we could see that they played a networked game, spent a lot of time at the TV Studio and the ORF archive, used the Abacus and spent some time at the thematic islands on messenger mail and telephones.

- A man aged 50-60 stands at the media.matrix reading intensely, with his card on the reader. 10 minutes later he is seen again, looking at old projection machines and cameras. Then he inspects the printing press. 20 minutes later he sits at the ORF archive, selectively watching clips for some 8 minutes. From first sighting to leaving, he spends at least 50 minutes in the exhibition. Yet his digital backpack is almost empty; he saved nothing, but spent a lot of time at the ORF archive, thematic islands on mail and telephones, and used the telegraphy installations, exemplifying historically interested visitors.

The questionnaire allowed us to compare card owners and non-owners for demographic traits. There were no differences in occupation, sex and most other issues. A significant difference was age (Kolmogorov-Smirnow and Mann-Whitney test). Card owners are on average (median) above 50 and non-owners between 30 and 50. Card-owners rated themselves as somewhat more computer-experienced and more often had come to the museum for the medien.welten exhibition. Tracking visitors' interaction with exhibits allowed further comparisons. E.g. at the ORF archive both groups spent the same amount of time, but card owners dedicated more time to specific clips and watched different clips. The hit list of the media.matrix visualized as a cartographic map reveals 'game' to be overall the most popular topic, but card-owners read on a broader range of topics and have a second local maximum for 'tele/convergence'. Card owners also significantly differ in their interaction sequence length in the digital room, and at all installations or exhibits (Kolmogorov-Smirnow and Mann-Whitney). This confirms interview results indicating card-owners to have more specific interest in the exhibition.

\section{Packpack Content: Using the SmartCard for Souvenirs}

Data analysis revealed a significant correlation between the amount of content in digital backpacks and summarized interaction time with installations. Images from the digitization booths take first place in backpack content 


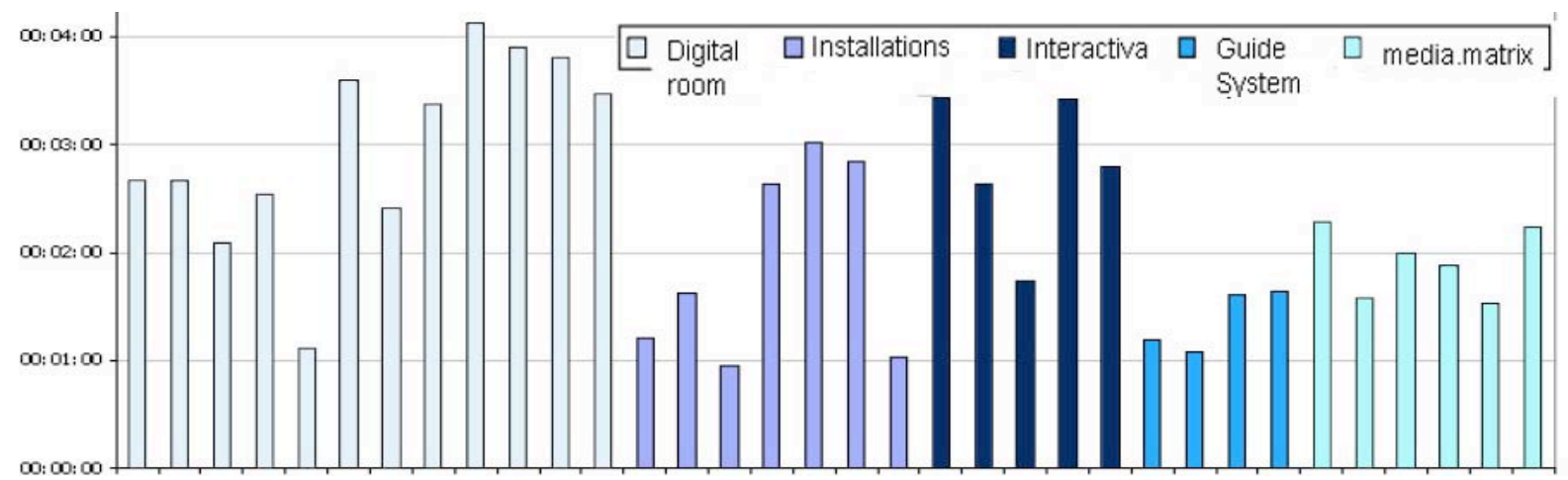

Fig. 7. Median session length by smart.card owners for all interactive stations, represented as bars (TV news is the peak in installations section; "interactiva" - the darkest section of bars - entails left to right: abacus, optical and electrical telegraphy exhibits, two ORF archives; 4 identical guide systems and 6 identical media.matrix are distributed throughout the exhibition)

(15\%), videos from the TV studio come second (10\%), followed by a set of game results, sound samples from the digitization booth $(9 \%)$ and videos from the ORF archive $(8 \%)$. During observation, the TV studio was almost always busy, often with a queue. Data analysis confirms that it has the largest number of sessions and the highest summarized usage time of all exhibits. The high number of game scores demonstrates the attractiveness of networked computer games in the digital room. These seemed to be used most often by school kids (on class trips) and children. A salient number of visitors tried sending messages, mostly from the digital room, at guide system terminals, or via internet. Recipients deleted ca. $40 \%$ of read messages. $20 \%$ were unread (probably because all cards that have been in use on a day are listed as possible recipients). The low number of animations from the Abacus contradicts its high usage at first sight. Observations revealed that only few visitors completed the rather lengthy calculation, not knowing that one needs to solve the entire task to receive a 'gift'.

Only every third backpack contains 'bookmarks' from the media.matrix. This number in combination with observation indicates that many visitors did not notice the function. Half furthermore had only set one bookmark. Possibly many visitors believe bookmarking saves the entire media.matrix. As some visitors used the online questionnaire comment to complain about missing data in their digital backpack, this might be a common misconception. The interviews also hinted at usability problems. Several visitors (mistakenly) assumed that interactive exhibits would only function in combination with the card ("I cannot use the exhibits without it?"). Many reported initial problems in using the card and not knowing what to do and how. A common mistake was only sweeping the card over the reader, believing it to be registered. During observation, nonworking card readers repeatedly irritated visitors. Therefore help on the smart.card has been redesigned since. On first use a visitor is presented with a short help window and is given direct access to profile personalization.

\section{Recommendations for Card Features and Handling}

Results show that visitors like the digital backpack concept and do not mind using the card explicitly - it becomes an object of discussion and coordination (cf. [1]) to be handed around. Main issues concern providing enough value to different types of visitors so as to market the card and ensure a satisfactory experience of the exhibition. Visitors who do not intend to spend much time in the exhibition are not inclined to buy a card. Instead we advise focusing on visitors with particular interest in the exhibition. Visitors interested in (computer) history make up a substantial fraction; for them the card could be made more attractive through historical or technical information about exhibits interacted with, regardless of solving given tasks or explicit saving. Card readers could be integrated at other exhibits, or cameras installed, so visitors can photograph themselves next to interesting exhibits. Visitors also asked for saving a set of videos in the TV studio for groups sharing a card. Visitors need feedback whether card readers work. In general usability needs to be ensured. Observations and questionnaire remarks revealed problems with saving data, e.g. missing videos (some visitors buy the card specifically for the TV studio video). Some problems might be due to visual misalignment on touch screens, so visitors only assume they saved. Furthermore some do not understand right away that they need to click a 'save' button to save something that has already been generated.

Several of our suggestions have been implemented since our project report. The threshold to buy is lowered with a ticket machine at the exhibition entrance. Many backpack contents have been redone or extended, e.g. an interactive simulation of the Abacus (inserted once interacting with it), of different types of telegraphy and the enigma (this is completely new content), the ability to save up to ten clips from the ORF archive (previously only one standard clip) and all content of the media.matrix (previous limit 13). Interaction with the card has been simplified and made more consistent, and profile configuration functionality stripped of superfluous features to reduce complexity.

\section{Experiences with Automatically Generated Data}

Figure 7 and 8 show mean session length and usage frequency for interactive exhibits. For most of these session time follows a declining exponential curve, consistent with other visitor interaction studies [14]. Installations and 
hands-on exhibits in general have longer sessions than media.matrix and guide system. Sessions at terminals in the digital room tended to be the longest, probably because of access to games, simulations, and internet surfing. Observation and interviews showed striking differences between visitor types and interest groups. While young people are primarily interested in modern media (cf. [15]), older people often circumvent these. Thus most visitors concentrate on familiar media instead of developing new interests. Only mixed media approaches - the computerenhanced hands-on exhibits - attracted visitors of all ages and interests. Providing more hands-on installations therefore seems a viable solution to engaging diverse visitor types and sparking interest in new topics (cf. [7]).

Regarding total usage time and number of sessions the TV studio scored highest. The Abacus is used on average 20 to $30 \%$ of a day (up to $50 \%$ ). It was used by almost all visitors (including those spending less than 10 minutes in the exhibition). The guide system has relative short sessions and was on average used only for $2-5 \%$ of its daily runtime. The interviews gave an explanation: visitors often simply want to "drift along" and not plan their path. Better used was the media.matrix, although faring way below hands-on exhibits or digital room terminals. Yet we found that most visitors only read the first from up to four pages on a topic. Despite of this large content, visitors complained about missing background information on exhibits. Thus more contextualized means of providing information might serve visitor needs better, allowing to "focus on the displayed objects" [7]. The museum now decided to make guide system and media.matrix accessible at all terminals, in particular in the digital room where people can sit down. Alternatively this content could as well be sold on a CD.

Data analysis provided evidence which card features and installations were used well and where people started using the card. Naturally with more long range readers [2] (or continuous tracking [4]) we could tell more about visitor paths and time spent at exhibits. Unfortunately demands of a subsequent evaluation had not been taken into account when planning and designing the software. Standardization of activity logging needs to be ensured for comparing installations. It was important to test data analysis

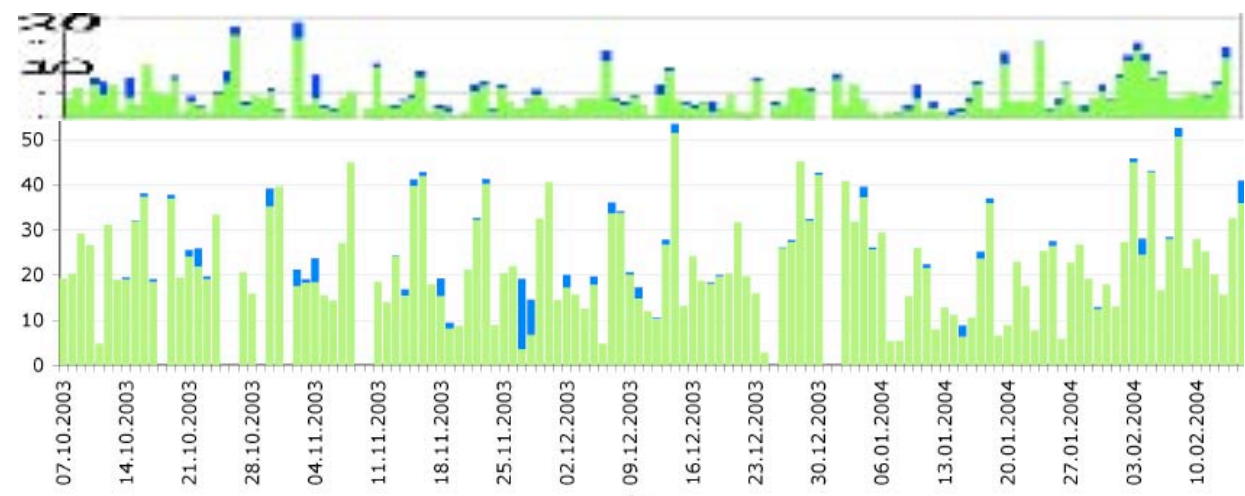

Figure 8. Guide system (above) and Abacus (below) use in \% of daily runtime over an identical time frame. The former remains well below $20 \%$. Cards represented in dark. instruments, whether they yield meaningful results, and to consider the origin of data. Use of complementary qualitative methods was very important for this grounding of data analysis and invaluable in giving context to results.

\section{DISCUSSION}

Most museum guide system evaluations reported on at $\mathrm{HCI} / \mathrm{CSCW}$ conferences are based on a small sample of visitors, often recruited outside of the museum and closely observed during a prototype test phase. We here reported on a long-term study of daily 'use', with those visitors that are there 'naturally'. This uncovers some of the practicalities involved, such as how many people will invest into the card if it is not for free and how the visitor experience can severely suffer if interactive installations do not function or have usability problems. Keeping installations running or helping visitors out demands significant staff effort (in this case there was only one technician for the entire floor). On a pragmatic level our study highlights that one needs to carefully target user groups in terms of facilities offered, so as to provide an incentive to buy the card - the implemented concept almost ignored the group that seemed most likely to invest into it, the historically interested.

Augmenting an exhibition with smartcards and a digital backpack differs from employing mobile, personal, contextsensitive guides [1, 2, 19]. Evaluation uncovered disadvantages of embedding information displays in the exhibition - while the display space is bigger, museums can not afford and will not want to distribute many displays in exhibitions. Furthermore decontextualized information (i.e. the media matrix) was not appreciated by visitors. Their comments as well as results from related work suggest that delivering relevant information in the vicinity of related exhibits would be superior. The provision of a souveniring function is still rare and often limited to provided data [3]. The digital backpack implemented here shares features of the "Rememberer" tool tested at the San Francisco Exploratorium [8], but saves more complex objects. Yet it is restricted to filling it with content while in the museum. Thus interest soon ceases after showing souvenirs around. Extensions could give access to online discussion forums that feed back into the exhibition, thereby intensifying the 'connect' theme (cf [6]).

Museums are an ideal test bed for technology and multimedia experiments. Even if efficiency is not a goal in this context, usability and user-centered design are important: visitors will only attend to what attracts their interest and expect value (content, fun, working exhibits) for their entrance fee. Our evaluation yielded insights which visitor types might be more explicitly and effectively addressed by card 
features, raising incentive for buying the card and improving visitor satisfaction. We could give detailed hints on where to invest effort into improving usability or adding content. Regarding interaction design, we note that stations allowing 'real' interactivity and creation of personal content (not just reading a hypertext) were more intensely used (cf. [15]) than those with 'flat', predefined interaction.

The smart.card data and the interaction logging from installations allowed us to analyze simple aspects of interaction behavior (duration, frequency, number, intensity of usage) quite well, but it does not tell us whether people are engaged with the content or just clicking around. Data analysis provided evidence of which card features and interactive exhibits were used well and which less. Observation and interviews helped us in detecting underlying causes, provided us with context necessary to understand what our data actually meant, and enabled us to develop specific ideas for improving the exhibition. Data analysis gave hints on usability issues and provided additional evidence for issues from observation and interviews. The multi-method approach chosen was, as we believe, essential for the success of our evaluation study. In particular we benefited from iterative refinement of data analysis instruments and study design, often discussing interim results, observations, puzzling evidences, and redesigning research questions and analysis instruments.

We believe that our evaluation results and our experiences with the methodical approach of combining automatically generated logfiles and ethnographically-oriented methods are relevant for domains outside the museum such as amusement parks, local tourist information systems e.g. in cities, or 'augmented shopping'. All of these deal with diverse types of users walking around, finding out about things, engaging in a diverse set of activities besides of using the system, and a quick turnaround of the user population.

\section{ACKNOWLEDGMENTS}

We thank TMW staff, especially Otmar Moritsch, and the visitors we worked with. This study was done at TU Vienna Institute of Design \& Assessment of Technology (igw).

\section{REFERENCES}

1. Aoki, P.M et al: Sotto Voce: Exploring the Interplay of Conversation and Mobile Audio Spaces. Proc. of CHI'02. ACM (2002). 431-438

2. Benelli, G. et al; HIPS Hyper-Interaction within Physical Space. Proc. of Int. Conference on Multimedia Computing and Systems. IEEE (1999). 1075-1078

3. Berkovich, M. et al.: Discovery Point: Enhancing the Museum Experience with Technology. Proc. of CHI'03. ACM (2003). 994-995

4. Bianchi, A., Zancanaro, M.: Tracking users' movements in an artistic physical space. Proc. of i3 Annual Conference (1999). 103-106
5. Blomberg, J. et al.: Ethnographic Field Methods and Their Relation to Design. In: Schuler, D., Namioka, A. (eds.) Participatory Design - Principles and Practices. Mahwah, N.J: Lawrence Erlbaum (1993). 123-155

6. Brown. B., et al. "Lessons from the Lighthouse: Collaboration in A Shared Mixed Reality System". Proceedings of CHI'03, N.Y.: ACM (2003), 577-584

7. Ciolfi, L.; Bannon, L.J.: Learning from Museum Visits: Shaping Design Sensitivities. Technical Report IDCUniversity of Limerick (2002)

8. Fleck, M. et al: Rememberer: A Tool for Capturing Museum Visits. Proc. of UbiComp'02 (2002). 48-55

9. Flick, U.: Qualitative Forschung. Rowohlt (2000)

10.Fraser, M., et al "Assembling History: Achieving Coherent Experiences with Diverse Technologies", Proc. of ECSCW'03, Kluwer (2003), 179-198

11.Heinecke, A.M.: Evaluation of Hypermedia Systems in Museums. Proc. of Int. Conference on Hypermedia and Interactivity in Museums ICHIM'95 / MCN'95. (1995)

12.Hornecker, E., Stifter, M. Evaluationsstudie Ausstellung medien.welten. Unpublished project report TU Vienna \& TMW, March (2004)

13.Hornecker, E., Stifter, M., Moritsch, O. Assessing Visitor Behavior and Attitudes in the medien.welten Exhibition. Proc. of CHI'04 Ext. Abstracts. ACM (2004). p. 1536

14.Kelly, L.: Use of Computer Interactives in Museum Exhibitions: Literature Review. AMARC - Australian Museum Audience Research Centre (2000) www. amonline.net.au/amarc/pdf/about/complitreview.pdf

15.Kelly, L.: What Do People Do When They Visit A Museum? AMARC (2002) - www.amonline. net.au/amarc/pdf/research/visitorbehaviour.pdf

16.Mackay, W.: Triangulation within and across HCI disciplines. A Commentary. Human Computer Interaction Journal 3(13) (1998). pp. 310-315

17.Moritsch, O., Pensold, W.: Das Projekt medien.welten Die Ausstellung medien.welten - medien.matrix smart.card. forum. magazin technisches museum wien 02. (2003). pp. 03-04, 05-06, 13, 15

18.Moritsch, O., Pensold, W.: medien.welten - Zweiter Akt. forum. magazin technisches museum wien 03. (2003). pp.03-06

19.Oppermann, R., Specht, M.: A nomadic Information System for Adaptive Exhition Guidance. Proc. of ICHIM'99 (1999)

20.Stifter, M. Quantitative Analyse des Besucherverhaltens - Evaluierung der Ausstellung medien.welten des Technischen Museums Wien mittels automatischprotokollierten Besucherinteraktionen. Diploma thesis TU Vienna (2005) 